\title{
QUALIDADE MICROBIOLÓGICA DE AMOSTRAS DE SALAME
}

\author{
FERNANDO LEITE HOFFMANN * \\ CRISPIN HUMBERTO GARCIA-CRUZ * \\ TÂNIA MARIA VINTURIM * \\ MURILO TONIOLO CARMELLO *
}

\begin{abstract}
Verificou-se a qualidade microbiológica de amostras de salame obtidas de uma indústria da região de São José do Rio Preto - SP. A confrontação dos resultados encontrados com a legislação federal vigente evidenciou que das quinze amostras de salame analisadas (100\%), somente cinco (33,3\%) apresentaram-se de acordo com os padrões microbiológicos e por conseguinte, apropriadas ao consumo.
\end{abstract}

\section{INTRODUÇÃO}

Os embutidos são produtos elaborados com carnes ou outros tecidos animais comestíveis, curados ou não, defumados e dessecados ou não, tendo como envoltório natural tripas, bexigas e outras membranas animais ou envoltório plástico apropriado (7).

Estes produtos alimentícios podem ser classificados, segundo o seu processo de fabricação, em frescos, cozidos, defumados ou secos; de acordo com a sua composição, em simples ou mistos e mesmo conforme suas características, em salame, chouriço, lingüiça, morcela, mortadela, paio, patê ou pasta, rolado ou queijo de porco, salsicha e salsichão (7).

\footnotetext{
Professores do Departamento de Engenharia e Tecnologia de Alimentos, Universidade Estadual
} Paulista, São José do Rio Preto, SP 
Considera-se salame como o produto constituído da mistura de carnes cruas bovina e suína, convenientemente condimentado, embutido em tripas finas de bovino, ovino, caprino ou vitela, e em seguida, submetido a defumação ou cozimento e dessecação a frio, conforme o tipo de salame. As carnes usadas no preparo deste produto devem ser cortadas em pedaços ou trituradas. Será permitida a adição de toucinho na proporção de 5 a $10 \%$ e ainda o emprego de carne de terceira de bovino, tal como acém, peito e pescoço. O salame, de acordo com o estilo de preparo e condimentação, poderá ainda ser classificado por tipos, ou seja, "milanês", "genovês", etc. (7).

As fases envolvidas no processamento do salame podem ser resumidas em: seleção, tratamento e moagem da matéria-prima, embutimento, maturação e secagem do salame. Em todos estes estágios devem prevalecer condições higiênicas rigorosas para não ocasionar contaminação microbiana do produto final, o que poderia causar a sua deterioração, bem como torná-lo impróprio para o consumo $(4,5,6)$.

Levando-se em conta os aspectos indesejáveis da contaminação microbiana desenvolveu-se o presente trabalho com o objetivo de verificar a qualidade microbiológica de amostras de salame obtidas de uma indústria da região de São José do Rio Preto - SP.

\section{MATERIAL E MÉTODOS}

\subsection{COLETA DAS AMOSTRAS}

Obteve-se quinze amostras de salame, logo após sua produção, em dias diferentes, e portanto, de lotes diferentes, de uma empresa da região de São José do Rio Preto - SP, que processa e comercializa carnes preparadas embutidas. Estas amostras foram transportadas adequadamente ao laboratório para análise imediata.

\subsection{PREPARO DAS AMOSTRAS}

Pesou-se assepticamente $10 \mathrm{~g}$ de amostra, transferindo-as para erlenmeyer contendo $90 \mathrm{~mL}$ de água destilada estéril para posterior homogeneização (diluição $10^{-1}$ ). A partir desta diluição efetuou-se as demais até $10^{-6}$. Estas seis diluições foram usadas em todas as análises microbiológicas, exceto quando especificado (3). 


\section{3}

CONTAGEM DE BACTÉRIAS AERÓBIAS MESÓFILAS

Pipetou-se assepticamente $1 \mathrm{~mL}$ das diluições anteriormente preparadas e colocou-se em placas de Petri devidamente identificadas. Adicionou-se 15 $\mathrm{mL}$ de ágar para contagem padrão em cada placa, homogeneizou-se, incubou-se a $35^{\circ} \mathrm{C}$ por 48 horas e calculou-se as unidades formadoras de colônias (3).

\subsection{ENUMERAÇÃO DE BOLORES E LEVEDURAS}

Pipetou-se assepticamente $1 \mathrm{~mL}$ das diluições e distribuiu-se em placas de Petri identificadas. Adicionou-se a cada placa $15 \mathrm{~mL}$ de ágar batata glicose acidificado com ácido tartárico a $10 \%(\mathrm{pH}=4,0)$, seguido de homogeneização. Após solidificação incubou-se a $25^{\circ} \mathrm{C}$ por 5 dias e calculou-se, de acordo com as diluições, as unidades formadoras de colônias (3).

\subsection{CONTAGEM DE CLOSTRÍDIOS SULFITO REDUTORES}

Pipetou-se assepticamente $1 \mathrm{~mL}$ das diluições e distribuiu-se em placas de Petri identificadas. Adicionou-se a cada placa $15 \mathrm{~mL}$ de ágar sulfito de polimixina sulfadiazina e homogeneizou-se. Depois da solidificação acrescentou-se ainda uma segunda camada do mesmo ágar em volume suficiente para cobrir a primeira. Após a solidificação incubou-se, em anaerobiose, a $44^{\circ} \mathrm{C}$ por 24-48 horas. Calculou-se, de acordo com as diluições, as unidades formadoras de colônias $(3,8)$.

\subsection{ENUMERAÇÃO DE Staphylococcus aureus}

Semeou-se em duplicata, sobre a superfície do ágar telurito-gema de ovo contido nas placas de Petri, $0,1 \mathrm{~mL}$ de cada diluição escolhida, com o auxílio de alça ou espátula de Drigalsky. O inóculo $(0,1 \mathrm{~mL})$ foi cuidadosamente espalhado por toda a superfície do meio até a sua total absorção. A seguir, as placas de Petri foram incubadas a $37^{\circ} \mathrm{C}$ por $24-48$ horas. Calculou-se, de acordo com as diluições, as unidades formadoras de colônias que se apresentaram negras, brilhantes, convexas e rodeadas por zonas claras de 2 a $5 \mathrm{~mm}$ de diâmetro. Estas foram submetidas aos testes bioquímicos de confirmação, principalmente termonuclease e coagulase $(3,8)$. 


\subsection{DETERMINAÇÃO DO NÚMERO MAIS PROVÁVEL DE COLIFORMES TOTAIS}

Foram inoculadas três séries de três tubos contendo $9 \mathrm{~mL}$ de caldo lauril sulfato triptose com $1 \mathrm{~mL}$ das diluições $10^{-1}, 10^{-2}$ e $10^{-3}$. Homogeneizou-se e incubou-se a $35^{\circ} \mathrm{C}$ durante 48 horas. $\mathrm{O}$ cálculo do número mais provável (NMP) de coliformes totais foi realizado com o auxílio da tabela de Hoskins (3).

\subsection{DETERMINAÇÃO DO NÚMERO MAIS PROVÁVEL DE COLIFORMES FECAIS}

Foi utilizada a técnica dos tubos múltiplos, usando-se o caldo EC. Após a inoculação, os tubos foram incubados a $44,5^{\circ} \mathrm{C}$ por 24 horas (3). O cálculo do NMP de coliformes fecais foi efetuado, também, com o auxílio da tabela de Hoskins.

\subsection{PESQUISA DE Escherichia coli}

Uma alíquota dos tubos contendo caldo EC, que apresentavam turbidez, com ou sem gás no interior do tubo de Durhan, foi semeada em placas de Petri contendo ágar eosina azul de metileno. As colônias suspeitas, que possuíam 2 a $3 \mathrm{~mm}$ de diâmetro e se apresentaram azuis com centro negro e bordas claras à luz transmitida, e brilho metálico esverdeado à luz refletida, foram identificadas com 0 uso de testes bioquímicos, principalmente o IMVIC $(1,3)$.

\subsection{PESQUISA DE Salmonella sp}

Em $225 \mathrm{~mL}$ de caldo lactosado e de água peptonada a 1\% foram homogeneizados, respectivamente, $25 \mathrm{~g}$ de produto. Os dois meios de cultura continham $0,5 \%$ de $\mathrm{Na}_{2} \mathrm{SO}_{3}$ (3). Após a incubação a $35^{\circ} \mathrm{C}$ por 24 horas, $1 \mathrm{~mL}$ de cada cultivo foi transferido para $10 \mathrm{~mL}$ de caldo tetrationato de Kauffmann e para $10 \mathrm{~mL}$ de caldo selenito cistina e incubados a $35^{\circ} \mathrm{C}$ e $43^{\circ} \mathrm{C}$. Depois de 24 horas, 48 horas e 5 dias foram efetuadas semeaduras em placas de Petri contendo ágar SS e ágar verde brilhante, sendo as colônias típicas suspeitas submetidas a testes bioquímicos (principalmente inoculação em ágar tríplice açúcar e ferro, em ágar lisina e ferro, teste de urease, degradação do malonato, desaminação da fenilalanina e descarboxilação da lisina) e sorológicos $(3,8)$. 
Os resultados das diferentes análises microbiológicas de amostras de salame estão demonstrados na Tabela 1.

Independentemente da existência de padrão microbiológico para este tipo de produto na legislação brasileira em vigor (2), quanto a bactérias aeróbias mesófilas, bolores e leveduras e coliformes totais, as análises foram reslizadas para que se tivesse uma idéia da carga microbiana inicial e das condições higiênico-sanitárias deste alimento (matéria-prima, ambiente e pessoal).

A contagem de bactérias aeróbias mesófilas variou de 1,2 × $10^{3}$ a 1,0 × $10^{9}$ UFC/g, a de bolores e leveduras de $1,0 \times 10^{1}$ a $4,0 \times 10^{6} \mathrm{UFC} / \mathrm{g}$ e a determinação do número mais provável de coliformes totais de $<3$ a 240 $\mathrm{NMP} / \mathrm{g}$.

Todas as amostras de salame (100\%) apresentaram para clostrídios sulfito redutores o resultado de $<10 \mathrm{UFC/g}$ e portanto dentro dos limites estabelecido pela Legislação Federal (2).

Segundo a Legislação Federal (2) das quinze amostras de salame analisadas (100\%), nove (60\%) estavam em desacordo com o padrão estabelecido para Staphylococcus aureus. De acordo com essa mesma legislação, duas $(22,2 \%)$ dessas nove amostras foram classificadas como "produtos em condições higiênico-sanitárias insatisfatórias" e sete $(77,8 \%)$, como "produtos potencialmente capazes de causar toxinfecções alimentares" e portanto "produtos impróprios para o consumo".

Apesar de duas (13,3\%) das quinze amostras analisadas terem apresentado resultados para coliformes fecais de 4 e $23 \mathrm{NMP} / \mathrm{g}$ e ter sido confirmada a presença de Escherichia coli, todas apresentaram-se de acordo com o padrão estabelecido pela Legislação Federal (2). Os resultados do IMVIC, para os microrganismos dessas duas amostras foram os seguintes: indol $(+)$, vermelho de metila $(+)$, Voges-Proskauer $(-)$ e citrato (-).

Com respeito a pesquisa de Salmonella sp, duas (13,3\%) das quinze amostras analisadas apresentaram-se em desacordo com o padrão da legislação em vigor (2), sendo classificadas como "produtos potencialmente capazes de causar toxinfecção alimentar" e portanto "produtos impróprios para o consumo". Os microrganismos encontrados nestas duas amostras apresentaram também resultados condizentes para o gênero Salmonella com relação à sorologia e testes bioquímicos, sendo urease negativos, não metabolizando o malonato, não desaminando a fenilalanina e apresentando resultados positivos para a descarboxilação da lisina. 
TABELA 1 - REPRESENTAÇÃO DOS RESULTADOS OBTIDOS DURANTE AS DIFERENTES ANÁLISES MICROBIOLÓGICAS

\begin{tabular}{lcccccccc}
\hline Salame & $\begin{array}{c}\text { Bactérias } \\
\text { aeróbias } \\
\text { mesófilas } \\
\text { (UFC/g) }\end{array}$ & $\begin{array}{c}\text { Bolores } \\
\text { e } \\
\text { leveduras } \\
\text { (UFC/g) }\end{array}$ & $\begin{array}{c}\text { Clostrídios } \\
\text { sulfito } \\
\text { redutores } \\
\text { (UFC/g) }\end{array}$ & $\begin{array}{c}\text { Staphylococcus } \\
\text { aureus } \\
\text { (UFC/g) }\end{array}$ & $\begin{array}{c}\text { Coliformes } \\
\text { totais } \\
\text { (NMP/g) }\end{array}$ & $\begin{array}{c}\text { Coliformes } \\
\text { fecais } \\
\text { (NMP/g) }\end{array}$ & $\begin{array}{c}\text { Escherichia } \\
\text { coli }\end{array}$ & $\begin{array}{c}\text { Salmonella } \\
\text { sp }\end{array}$ \\
(confirmativo)
\end{tabular}




\section{CONCLUSÃO}

Os resultados deste trabalho permitem concluir que, das quinze amostras analisadas, somente cinco $(33,3 \%)$ encontravam-se em condições higiênico-sanitárias adequadas e portanto apropriadas ao consumo. Tal fato é preocupante, uma vez que este tipo de produto é consumido "in natura", sem nenhum tipo de tratamento térmico que possa reduzir o número de microrganismos capazes de ocasionar toxinfecções. É sabido que para provocar toxinfecção é necessário que o patógeno atinja concentração elevada no alimento, ou produza toxinas durante sua multiplicação. Isto poderá ocorrer no alimento em questão, mesmo sendo ácido, tendo baixa atividade de água, grande microbiota competidora e conservadores químicos.

\section{Abstract}

The aim of this work was to determine the microbiological quality of salami samples produced in a specific industry from São José do Rio Preto, State of São Paulo, Brazil. The analytical results showed that, among fifteen samples, only five (33.3\%) were suitable for consumption, according to Brazilian legislation.

\section{REFERÊNCIAS BIBLIOGRÁFICAS}

1 AMERICAN PUBLIC HEALTH ASSOCIATION. Métodos recomendados para o exame microbiológico de alimentos. São Paulo : Polígono, 1972.

2 BRASIL. Portaria n. 001 de 28 de janeiro de 1987. Aprova padrões microbiológicos para alimentos. Diário Oficial [da República Federativa do Brasil], Brasília, 25 de fevereiro de 1987.

3 INTERNATIONAL COMMISSION ON MICROBIOLOGICAL SPECIFICATIONS FOR FOODS (ICMSF). Microorganisms in foods: their significance and methods of enumeration. 2. ed. Toronto : University of Toronto Press, 1978. v. 1.

4 DELAZARI, I. Microbiologia de carnes. Boletim do ITAL, Campinas, v. 52, p. 25-60, jul./ago., 1977.

5 DELAZARI, I. Microbiologia de carnes: microrganismos causadores de deterioração da carne e produtos cárneos. Boletim Informativo da Sociedade Brasileira de Ciência e Tecnologia de Alimentos, Campinas, v. 49, p. 3-39, set. 1979. 
6 LEITÃO, M.F.F. Microrganismos patogênicos na carne e derivados.

Boletim do ITAL, Campinas, v. 59, p. 15-48, set./out. 1978.

7 SÃO PAULO (Estado). Decreto n. 12.486 de 20 de outubro de 1978. Aprova normas técnicas especiais relativas a alimentos e bebidas. Diário Oficial, São Paulo, 21 de outubro de 1978.

8 SPECK, M.L. Compendium of methods for the microbiological examination of foods. 2. ed. Washington: APHA, 1984. 